\title{
ADMINISTRAÇÃO INTERCULTURAL
}

Os estudos interculturais são recentes e de natureza eminentemente empírica. Há duas correntes principais. A anglosaxã, que utiliza a terminologia "cross-cultural" e se caracteriza por pesquisas comparativas das culturas a partir de diferenças nacionais e internacionais, com forte apoio de instrumental quantitativo. E a européia, que se denomina "intercultural" e desenvolve pesquisa interacionista sobre as conseqüências dos encontros interculturais, privilegiando a interpretação no contato. Os principais focos de pesquisa desse tema são processos migratórios, coordenação de equipes multiculturais, expatriação profissional, estratégias de fusão e aquisição considerando as diferentes culturas. Maria Ester de Freitas, professora da FGV-EAESP, recomenda as seguintes indicações:

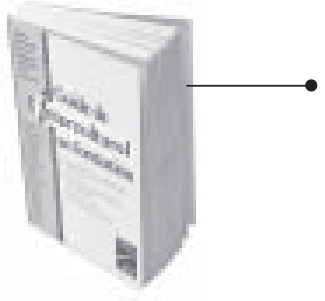

GUIDE DE L'INTERCULTUREL EN FORMATION. J. Demorgon e E. M. Lipiansky (Orgs.). Paris: Retz, 1999. 349 p. Coletân ea que abriga contribuições de autores de diversas nacionalidades, a obra situa a problemática intercultural em diferentes áreas, como a educação, o trabalho social e de saúde, a economia e a empresa, a mídia e a imprensa, bem como discute os atores e suas culturas. A interpretação das comunicações interculturais é um tema central, pois trata de códigos, línguas, percepções, identidades, alteridade, contatos culturais, aculturações e interculturações. É uma obra que situa o leitor nesse universo aberto a invenções, descobertas e construções coletivas.

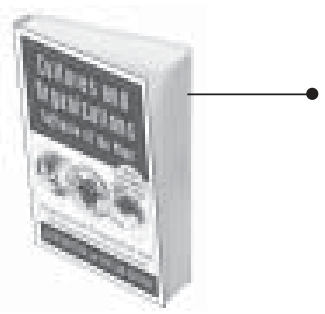

CULTURE AND ORGANIZATIONS: Software of the Mind. G. Hofstede. Nova York: McGraw-Hill, 1997. 279 p.

0 estudo de Hofstede, realizado nos anos 1980, é considerado uma referência-chave da corrente cross-cultural, trazendo uma pesquisa comparativa inédita junto à IBM, em mais de 50 países, e inovando na discussão das relações entre a cultura nacional e a organizacional. Este livro reformula a obra anterior do autor e incorpora novas pesquisas tanto do autor como de outros. A parte IV é especialmente dedicada aos encontros interculturais em diversas frentes: turismo, educação, cooperação e desenvolvimento, migrações, negócios e negociações.

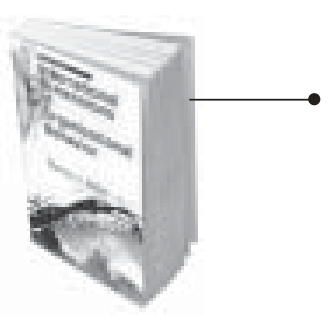

INTERNATIONAL DIMENSIONS OF ORGANIZATIONAL BEHAVIOR. N. Adler. Cincinnati: South-Western/ Thomson Learning, 2000. $391 \mathrm{p}$.

O trabalho da professora da M cGill University é uma referência importante na área e é considerado um clássico na bibliografia cross-cultural e intercultural. A autora traça um panorama competente do impacto da cultura nas organizações, da diversidade cultural tanto no trabalho de equipes multiculturais como na tomada de decisão e na negociação de nível global. Ela também apresenta um importante estudo desenvolvido com executivos americanos expatriados e uma discussão sobre carreiras globais.

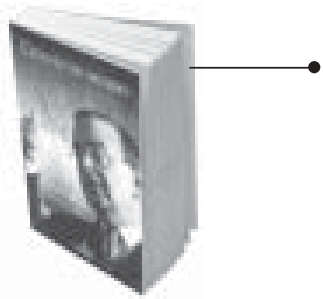

O CIDADÃo DO MUNDO. Carlos Ghosn e Philippe Reis. São Paulo: A Girafa, 2003. 400 p.

Reis é o jornalista que descreve a experiência de Ghosn, cumulativamente presidente da $\mathrm{N}$ issan e da Renault. A obra atrai pelas seguintes razões: a biografia pessoal e familiar de Ghosn, originada de fontes culturais diversas; sua rica experiência profissional e múltiplas expatriações (França, Brasil, Estados Unidos e Japão); a elaboração e implementação de um plano estratégico de salvação da Nissan, com apoio de uma equipe mista de executivos japoneses e franceses, e a "vantagem" de poder ser considerado uma pessoa que não possui uma raiz cultural predominante, sendo o que ele próprio denomina uma pessoa multicultural.

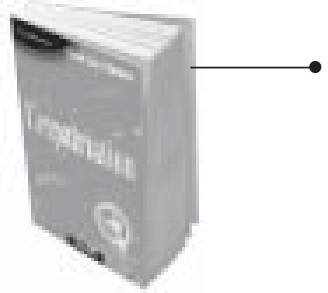

L'EXPATRIATION. Jean-Luc Cerdin. Paris: Éditions d'Organisation, 2002. 320 p.

0 autor desenvolve diferentes aspectos da decisão da empresa de expatriar profissionais e dos próprios profissionais de aceitarem essas missões. 0 estudo se baseia numa amostra de 293 executivos franceses em 44 países. Cerdin explora temas como o papel da adaptação, as motivações desses executivos para se expatriar, as situações de carreira e a mobilidade internacional, as características do trabalho e possíveis suportes, além das diversas categorias de novidades que são vividas pelos expatriados e os custos do fracasso. Atualmente é o estudo francês mais amplo sobre 0 assunto. 